\title{
Adsorptive removal of antibiotics from water using magnetic ion exchange resin
}

\author{
Tianyue Wang ${ }^{1,2}$, Xun $\mathrm{Pan}^{3}$, Weiwei Ben ${ }^{1, *}$, Jianbing Wang ${ }^{2}$, Pin $\mathrm{Hou}^{2}$, Zhimin Qiang ${ }^{1}$ \\ 1. Key Laboratory of Drinking Water Science and Technology, Research Center for Eco-Environmental Sciences, Chinese Academy of Sciences, \\ Beijing 100085, China \\ 2. School of Chemical and Environmental Engineering, Beijing Campus, China University of Mining and Technology, Beijing 100083, China \\ 3. Foreign Economic Cooperation Office, Ministry of Environmental Protection, Beijing 100035, China
}

\section{A R T I C L E I N F O}

\section{Article history:}

Received 31 December 2015

Revised 22 March 2016

Accepted 24 March 2016

Available online 27 April 2016

\section{Keywords:}

Sulfamethoxazole

Tetracycline

Amoxicillin

Antibiotics

MIEX resin

Adsorption

\begin{abstract}
A B S T R A C T
The occurrence of antibiotics in the environment has recently raised serious concern regarding their potential threat to aquatic ecosystem and human health. In this study, the magnetic ion exchange (MIEX) resin was applied for removing three commonly-used antibiotics, sulfamethoxazole (SMX), tetracycline (TCN) and amoxicillin (AMX) from water. The results of batch experiments show that the maximum adsorption capacities on the MIEX resin for SMX, TCN and AMX were 789.32, 443.18 and $155.15 \mu \mathrm{g} / \mathrm{mL}$ at $25^{\circ} \mathrm{C}$, respectively, which were 2-7 times that for the powdered activated carbon. The adsorption kinetics of antibiotics on the MIEX resin could be simulated by the pseudo-second-order model $\left(R^{2}=0.99\right)$, and the adsorption isotherm data were well described by the Langmuir model $\left(R^{2}=0.97\right)$. Solution $\mathrm{pH}$ exhibited a remarkable impact on the adsorption process and the absorbed concentrations of the tested antibiotics were obtained around the neutral $\mathrm{pH}$. The MIEX resin could be easily regenerated by $2 \mathrm{~mol} / \mathrm{L} \mathrm{NaCl}$ solution and maintained high adsorption removal for the tested antibiotics after regeneration. Anion exchange mechanism mainly controlled the adsorption of antibiotic and the formation of hydrogen binding between the antibiotic and resin can also result in the increase of adsorption capacity. The high adsorption capacity, fast adsorption rate and prominent reusability make the MIEX resin a potential adsorbent in the application for removing antibiotics from water.
\end{abstract}

C 2016 The Research Center for Eco-Environmental Sciences, Chinese Academy of Sciences. Published by Elsevier B.V.

\section{Introduction}

Antibiotics have been widely used in veterinary and human medicine, but these compounds pose potential risks to human health and aquatic ecology when released into the environment (Watkinson et al., 2009). Now their residues have been detected worldwide in aquatic environment including surface, ground, and even drinking water (Nikolaou et al., 2007; Kim et al., 2010). Although the concentrations were generally reported to be in the range of ng/L to $\mu \mathrm{g} / \mathrm{L}$ levels, long-term exposure even to the low level of antibiotics could induce chronic allergic reactions, toxic effects and potential development of antibiotic resistant bacteria (Boxall et al., 2003; Baquero et al., 2008).

\footnotetext{
* Corresponding author. E-mail: wwben@rcees.ac.cn (Weiwei Ben).
} 
As conventional water treatment processes, such as coagulation, flocculation, sedimentation and ultraviolet irradiation, were relatively ineffective in eliminating antibiotics from water (Adams et al., 2002; Huerta-Fontela et al., 2011), some novel technologies including nanofiltration, reverse osmosis, advanced oxidation and adsorption have been developed in recent years. However, the use of membrane separation technologies is hampered by the problem of membrane fouling, and advanced oxidation processes may cause the formation of undesirable oxidation by-products, which hinder their popularization in water treatment plants. Adsorption is considered as an effective method to remove antibiotics from water. Activated carbon is the most widely used adsorbent in water treatment for the removal of organic micro-pollutants. Nevertheless, it is also known as a broad-spectrum adsorbent presenting lower selectivity for antibiotics (Choi et al., 2008), and high cost is needed to regenerate the activated carbon. Thus, more highly-selective and easily-regenerative adsorbents need to be explored for effectively removing antibiotics from water.

Magnetic ion exchange resin (MIEX) is a strong base anion exchange resin with iron oxide integrated into a macroporous, polyacrylic matrix, and is typically used with chloride as the exchangeable ion. In contrast to traditional anion exchange resins, the MIEX resin has a larger surface area due to the very small resin bead size. The average size in diameter of MIEX resin is 150-180 $\mu \mathrm{m}$ (2-5 times smaller than traditional resins), which may lead to fast adsorption of pollutants on the MIEX resin surface (Fearing et al., 2004; Hsu and Singer, 2010). Furthermore, the saturated resin can be easily regenerated using brine (Kitis et al., 2007). It was reported that the MIEX resin was effective in removing natural organic matter (NOM) from drinking water sources at relatively low dose (i.e., $5 \mathrm{~mL} / \mathrm{L}$ ), whilst bromide can be removed to different levels from water depending on the alkalinity and initial bromide ion concentration (Boyer and Singer, 2005). The adsorption efficiencies of MIEX resin for micro-pollutants from water were also studied. Humbert et al. (2008) evaluated the removal of two pesticides (i.e., atrazine and isoproturon) from surface water using a series of strong anion exchange resins. The results showed that the MIEX resin dosage of $8 \mathrm{~mL} / \mathrm{L}$ only brought about the removal of $7 \%$ and $5 \%$ for atrazine and isoproturon, respectively. As for 2, 4-dichlorophenoxyacetic acid, a widely used herbicide on crops, the removal efficiency was greater than $80 \%$ at MIEX resin dosage of $1 \mathrm{~mL} / \mathrm{L}$ (Ding et al., 2012). These results suggest that the removal efficiencies of micro-pollutants with MIEX resin are closely related to the characteristics of the target objects. To the best of our knowledge, the research about the removal of antibiotics by MIEX resin adsorption is still very limited.

This study aimed to investigate the adsorptive removal of three representative antibiotics from water using MIEX resin. The selected antibiotics were sulfamethoxazole (SMX), tetracycline (TCN) and amoxicillin (AMX), which were detected with high frequency in the aquatic environment (Heberer, 2002). The adsorption kinetics and isotherms of antibiotic on the MIEX resin were determined through batch experiments, and the removal mechanism was explored. In addition, the adsorption isotherms of these antibiotics on powdered activated carbon (PAC) were studied for comparison.

\section{Materials and methods}

\subsection{Chemicals and materials}

Three antibiotics (SMX, TCN and AMX) were purchased from Sigma-Aldrich (St. Louis, MO, USA). The organic solvents, methanol and acetonitrile, were of high performance liquid chromatography grade. Other chemicals were purchased from Beijing Chemical Reagents Company (Beijing, China) with analytical grade. The MIEX resin was virgin resin provided by Orica Watercare (Melbourne, Australia). The stock solution of antibiotics was prepared individually at a concentration of $100 \mathrm{mg} / \mathrm{L}$ in ultrapure water, which was produced by a Milli-Q system (Advantage A10, Millipore, Billerica, MA) with a resistivity of $\approx 18.2 \mathrm{M} \Omega$. The major physicochemical properties of the selected antibiotics are provided in Table 1.

\subsection{Experimental setup}

To determine the adsorption kinetics of antibiotics on MIEX resin, batch experiments were conducted in magnetically stirred $100 \mathrm{~mL}$ glass conical flasks at room temperature of $25 \pm 0.5^{\circ} \mathrm{C}$. Each flask was added with $250 \mu \mathrm{L}$ MIEX resin and $50 \mathrm{~mL}$ of an aqueous antibiotic solution at an initial concentration of 20, 100 and $500 \mu \mathrm{g} / \mathrm{L}$, respectively. The solution $\mathrm{pH}$ was not controlled, which changed by less than 0.2 units after adsorption. A series of $1 \mathrm{~mL}$ of samples were taken out at pre-selected reaction times and were filtered through $0.22 \mu \mathrm{m}$ PES syringe filters (Pall, USA). The residual antibiotic concentration was determined. Control experiments with $50 \mathrm{~mL}$ of aqueous antibiotic solution were conducted simultaneously in the absence of MIEX resin for comparison purposes. The adsorption isotherms were performed with a series of different initial antibiotic concentrations ranging from 100 to $5000 \mu \mathrm{g} / \mathrm{L}$, the dose of MIEX resin and PAC were set as $5 \mathrm{~mL} / \mathrm{L}$ and $20 \mathrm{mg} / \mathrm{L}$, respectively. The adsorption experiment lasted for $30 \mathrm{~min}$, which was sufficient to reach equilibrium. The effect of $\mathrm{pH}$ on the adsorption of antibiotics was evaluated with varying initial $\mathrm{pH}$ of solution from 3 to 11 by adding $0.1 \mathrm{~mol} / \mathrm{L} \mathrm{HCl}$ or $0.1 \mathrm{~mol} / \mathrm{L} \mathrm{NaOH}$ solution. All experiments were performed in duplicate.

\begin{tabular}{|c|c|c|c|c|c|}
\hline Antibiotics & $\begin{array}{l}\text { Chemical } \\
\text { formula }\end{array}$ & $\begin{array}{l}\text { Molecular } \\
\text { weight }\end{array}$ & Molecular structure & ${\mathrm{p} K \mathrm{a}^{\mathrm{a}}}$ & $\log K_{\text {ow }}{ }^{b}$ \\
\hline SMX & $\mathrm{C}_{10} \mathrm{H}_{11} \mathrm{~N}_{3} \mathrm{O}_{3} \mathrm{~S}$ & 253.28 & & $\begin{array}{l}1.85 \pm 0.30 \\
5.60 \pm 0.04\end{array}$ & 0.89 \\
\hline TCN & $\mathrm{C}_{22} \mathrm{H}_{24} \mathrm{~N}_{2} \mathrm{O}_{8}$ & 444.43 & & $\begin{array}{l}3.32 \pm 0.10 \\
7.78 \pm 0.15\end{array}$ & -1.37 \\
\hline AMX & $\mathrm{C}_{16} \mathrm{H}_{19} \mathrm{~N}_{3} \mathrm{O}_{5} \mathrm{~S}$ & 365.40 & & $\begin{array}{l}2.00 \pm 0.10 \\
7.49 \pm 0.10\end{array}$ & 0.87 \\
\hline & & & & $9.63 \pm 0.10$ & \\
\hline
\end{tabular}




\subsection{Analysis of antibiotics}

The concentrations of selected antibiotics were determined by ultra-performance liquid chromatography-tandem mass spectrometry (UPLC-MS/MS, Waters, Milford, MA, USA) coupled with an Agilent Zorbax SB-C18 column (100 $\mathrm{mm} \times$ $2.1 \mathrm{~mm}, 1.8 \mu \mathrm{m})$. Formic acid $(0.2 \%, \mathrm{~V} / \mathrm{V})$ and acetonitrile were used as mobile phases $\mathrm{A}$ and $\mathrm{B}$, respectively, with a total flow rate of $0.3 \mathrm{~mL} / \mathrm{min}$ at $30^{\circ} \mathrm{C}$. SMX, TCN and AMX were individually analyzed under an isocratic elution condition of 65:35, 85:15 and 80:20 (A:B), respectively. The injection volume was $5 \mu \mathrm{L}$. The mass spectrometer was operated under the positive electrospray ionization (ESI + ) mode and the selected ion recording (SIR) mode was chosen to quantify the antibiotics. The other MS parameters were described in Appendix A Table S1 via our previous studies (Ben et al., 2008).

\section{Results and discussion}

\subsection{Adsorption kinetics}

As shown in Fig. 1, a rapid initial adsorption for all three antibiotics was observed in the first $10 \mathrm{~min}$, and the initial rate of adsorption was greater for higher initial concentration

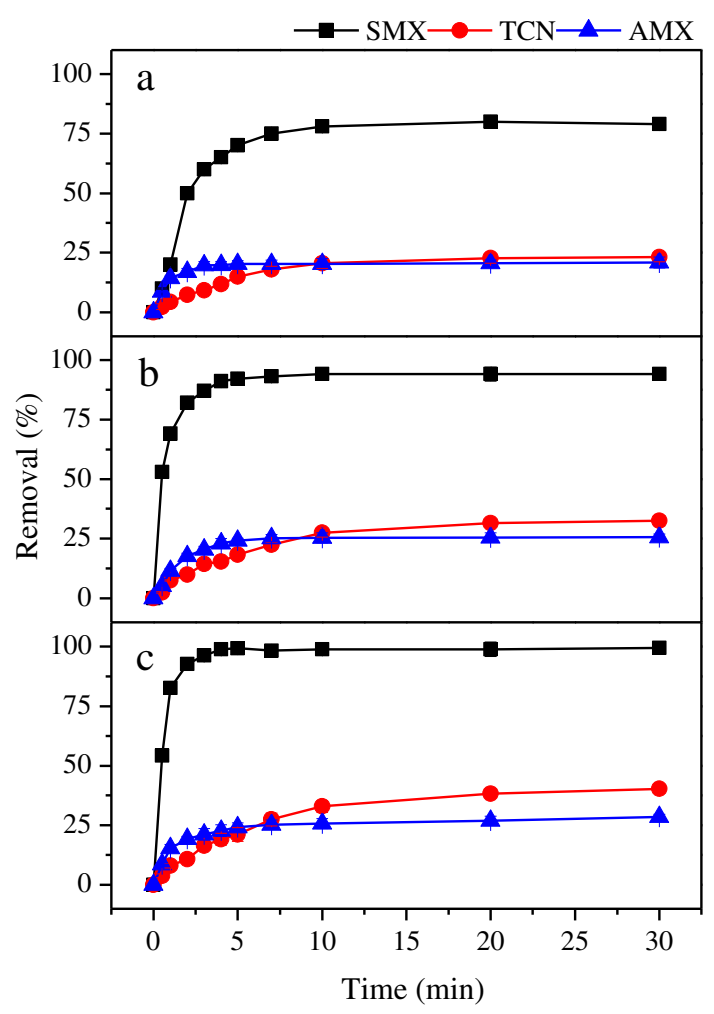

Fig. 1 - Removal of the selected antibiotics by magnetic ion exchange (MIEX) resin as a function of contact time.

(a) $C_{o}$, antibiotic $=20 \mu \mathrm{g} / \mathrm{L}$; (b) $C_{o}$, antibiotic $=100 \mu \mathrm{g} / \mathrm{L}$;

(c) $C_{o}$, antibiotic $=500 \mu \mathrm{g} / \mathrm{L}$. Experimental conditions: temperature $=25 \pm 0.5^{\circ} \mathrm{C}$, MIEX resin dosage $=5 \mathrm{~mL} / \mathrm{L}, \mathrm{pH}$ without any adjustment. Error bars represent the relative percent difference of duplicate experiments. of antibiotics, thereafter, the adsorption rate decreased gradually. The adsorption equilibrium was reached at $30 \mathrm{~min}$. The fast initial adsorption rate was attributed to the great availability of resin exchange sites. Along with the extension of adsorption time, the vacant sites on the surface of MIEX resin were mostly occupied, resulting in the decrease of the adsorption rate. Fig. 1 also indicates that the final removal efficiencies of MIEX resin for three antibiotics followed a descending order of SMX > TCN > AMX.

To further understand the adsorption kinetics of antibiotics using MIEX resin, experimental data were analyzed using pseudo-second-order model (Eq. (1)) (Ho and McKay, 1999):

$\frac{t}{q_{t}}=\frac{1}{k_{2} q_{e}^{2}}+\frac{1}{q_{e}} t$

where, $k_{2}(\mathrm{~mL} /(\mu \mathrm{g} \cdot \mathrm{min}))$ is the adsorption rate constant; and $q_{t}$ $(\mu \mathrm{g} / \mathrm{mL})$ and $q_{e}(\mu \mathrm{g} / \mathrm{mL})$ represent the adsorbed concentrations of antibiotic at time $t$ ( $\mathrm{min}$ ) and at equilibrium, respectively. Values of $k_{2}$ and $q_{e}$ can be calculated from the plot of $t / q_{t}$ against t. The initial adsorption rate $h(\mu \mathrm{g} /(\mathrm{mL} \cdot \mathrm{min}))$ can be obtained according to the following Eq. (2):

$h=k_{2} q_{e}^{2}$.

Table 2 shows the pseudo-second-order rate constants for the adsorption of three antibiotics. The linear correlation coefficients $\left(R^{2}\right)$ were all above 0.99 , clearly indicating that the pseudo-second-order kinetic model described the adsorption behavior of these antibiotics on the MIEX resin very well.

It is observed from Table 2 that at a certain dosage of MIEX resin, the adsorption rate $(h)$ increased gradually with the increase of initial concentration of antibiotics, while $k_{2}$ value decreased. This result implies that the MIEX resin hosted faster adsorption rate when processing higher initial concentration of antibiotics. Higher concentration of antibiotics could bring about stronger driving force to accelerate the diffusion of antibiotics from the antibiotic solution onto absorbent (Özacar, 2003; Sun and $\mathrm{Xu}, 1997)$, leading to a higher $h$ value.

As mentioned above, the adsorption rates of MIEX resin for different antibiotics exhibited a decreasing order for SMX, AMX and TCN, respectively. This was probably because of their different molecular weights, structures and hydrophobicity. Relatively lower molecular weight, simpler molecular structure and stronger hydrophobicity may increase the free energy of adsorbate from the polar aqueous solution, which was beneficial to the adsorption on the MIEX resin (Li and Sengupta, 1998).

The adsorption kinetic in water may be controlled by the external, interfacial or internal diffusion process (Qiang et al., 2013). The authors herein applied Eq. (3) to evaluate the intraparticle diffusion of antibiotics on MIEX (Weber and Morris, 1962):

$q_{\mathrm{t}}=k_{\mathrm{id}} \mathrm{t}^{1 / 2}+\mathrm{C}$

where $k_{\text {id }}\left(\mu \mathrm{g} /\left(\mathrm{mL} \cdot \mathrm{min}^{1 / 2}\right)\right)$ is the intraparticle diffusion rate constant and $C(\mu \mathrm{g} / \mathrm{mL})$ is the intraparticle diffusion constant.

According to Eq. (3), if the kinetic process is dominated by the intraparticle diffusion, the plot of $q_{t}$ versus $t^{1 / 2}$ should be a 
Table 2 - Adsorption kinetic parameters fitted with pseudo-second-order equation for antibiotics on MIEX resin.

\begin{tabular}{|c|c|c|c|c|c|}
\hline & & $q_{\mathrm{e}}(\mu \mathrm{g} / \mathrm{mL})$ & $k_{2}(\mathrm{~mL} /(\mu \mathrm{g} \cdot \min ))$ & $R^{2}$ & $h(\mu \mathrm{g} /(\mathrm{mL} \cdot \min ))$ \\
\hline \multirow[t]{3}{*}{$C_{o}$, antibiotic $=20 \mu \mathrm{g} / \mathrm{L}$} & SMX & 3.10 & 0.29 & 0.995 & 2.79 \\
\hline & TCN & 1.68 & 0.10 & 0.994 & 0.28 \\
\hline & AMX & 1.08 & 1.31 & 0.999 & 1.53 \\
\hline \multirow[t]{3}{*}{$C_{o}$, antibiotic $=100 \mu \mathrm{g} / \mathrm{L}$} & SMX & 17.89 & 0.24 & 0.999 & 76.81 \\
\hline & TCN & 9.99 & 0.02 & 0.996 & 2.00 \\
\hline & AMX & 5.29 & 0.25 & 0.999 & 7.00 \\
\hline \multirow[t]{3}{*}{$C_{o}$, antibiotic $=500 \mu \mathrm{g} / \mathrm{L}$} & SMX & 99.01 & 0.17 & 0.999 & 1666.51 \\
\hline & TCN & 27.78 & 0.01 & 0.992 & 7.72 \\
\hline & AMX & 21.10 & 0.14 & 0.999 & 62.33 \\
\hline
\end{tabular}

straight line. As shown in Appendix A Fig. S1, the plots of $q_{t}$ versus $t^{1 / 2}$ do not give linear forms within a poor correlation, indicating that the intraparticle diffusion was not a ratelimiting step.

\subsection{Adsorption isotherms}

The classic Langmuir isotherm model was applied to simulate the data of antibiotic adsorption on the MIEX resin and PAC, respectively. The isotherm equation is given as follow:

$q_{e}=\frac{k_{\mathrm{L}} q_{m} C_{e}}{1+k_{\mathrm{L}} C_{e}}$

where $q_{e}(\mu \mathrm{g} / \mathrm{mL})$ is the adsorbed concentration of antibiotic at equilibrium, $q_{m}(\mu \mathrm{g} / \mathrm{mL})$ is the maximum adsorption capacity, $C_{e}$ $(\mu \mathrm{g} / \mathrm{L})$ represents the equilibrium concentration of antibiotic in aqueous solution, and $k_{\mathrm{L}}(\mathrm{L} / \mu \mathrm{g})$ is the Langmuir constant.

Fig. 2 demonstrates that the adsorption isotherms for all the three antibiotics followed Langmuir isotherm over the concentration range studied. The model simulation parameters are listed in Table 3 , where good regressions $\left(R^{2}>0.97\right)$ were observed. The maximum adsorption capacities $\left(q_{m}\right)$ of MIEX resin for SMX, TCN and AMX, which obtained by nonlinear curve fitting, were 789.32, 443.18 and $155.15 \mu \mathrm{g} / \mathrm{mL}$, respectively. The adsorption capacities of PAC for the tested antibiotics obtained with this experimental configuration were lower as compared with MIEX resin, which were 104.12, 223.97 and $42.89 \mu \mathrm{g} / \mathrm{mg}$ for SMX, TCN and AMX, respectively. Besides higher adsorption capacities, MIEX resin also presented higher adsorption rates for the tested antibiotics than PAC (Appendix A Fig. S2).

\subsection{Effect of $p H$}

The $\mathrm{pH}$ value of solution affects the adsorption performance, since it can alter both the surface property of adsorbent and the speciation of the adsorbate in the solution (Abburi, 2003). The effect of $\mathrm{pH}$ on the adsorptive removal of these three antibiotics with MIEX resin is shown in Fig. 3. It can be observed that the adsorbed concentrations of tested antibiotics on the MIEX were around $20 \mu \mathrm{g} / \mathrm{mL}$ at pH 3. The removal of antibiotics increased with the increase of $\mathrm{pH}$ and the highest adsorbed concentrations were obtained at $\mathrm{pH} 7$, which were 199.54, 48.12 and $42.07 \mu \mathrm{g} / \mathrm{mL}$ for SMX, TCN and AMX, respectively. As the $\mathrm{pH}$ further increased from 7 to
9, the adsorbed concentrations of antibiotics on the MIEX resin decreased thereafter. Finally, at $\mathrm{pH}=11$, the adsorbed concentrations were observed only a slight decrease because the further increase of $\mathrm{pH}$ had little impact on the speciation of antibiotics and the surface charge of MIEX resin.

\subsection{Proposed adsorption mechanisms}

According to the results of adsorption experiments, it can be observed that: (1) the adsorbed concentration of SMX on the MIEX resin was obviously higher than that of TCN and AMX, especially at neutral and alkaline conditions; (2) the adsorption concentrations of antibiotics on the MIEX resin under neutral condition was higher than that at acid and alkaline conditions, especially for SMX.

The major mechanism of anion exchange is proposed to explain the effect of $\mathrm{pH}$ on the adsorption of antibiotics, which concludes that the adsorption process of these antibiotics on MIEX resin may be predominated by sharing or exchanging the electrons between the active sites and antibiotics (Deng et al., 2009).

Under the neutral condition $(\mathrm{pH}=7)$, the total SMX in solution consisted of more anionic form (90\%) than TCN and AMX (20\%-30\%), as showed in Appendix A Fig. S3, which could occupy more ion exchange sites provided by the quaternary ammonium functional group on the surface of MIEX resin (Neale et al., 2010). Hence, the higher adsorption capacity of SMX than that of TCN and AMX is caused by the more effective ion exchange performance (Fig. 4a).

Moreover, the dissociation sites for SMX, TCN and AMX at $\mathrm{pH}=7$ were sulfamide group, phenolic hydroxyl group and carboxyl group, respectively (Qiang and Adams, 2004; Homayoonfal and Mehrnia, 2014). The deprotonated form of sulfamide group was a relatively stronger anion than that of phenolic hydroxyl group and carboxyl group (Chen et al., 2013). Hence, compared to $\mathrm{TCN}^{-}$and $\mathrm{AMX}^{-}, \mathrm{SMX}^{-}$tends to strongly bind with the quaternary ammonium compounds on the MIEX resin by electrostatic attraction.

When the $\mathrm{pH}$ value decreased from 7 to 3 , the proportion of the neutral form for the antibiotics in the solution increased as the low $\mathrm{pK}_{\mathrm{a}, 1}$ of $1.85,3.32$ and 2.68 for SMX, TCN and AMX, respectively, and some of them could not be removed by ion exchange. Another part of the cationic form for the antibiotics would greatly weaken the adsorption on the MIEX resin due to electrostatic repulsion force. So the adsorbed concentrations 


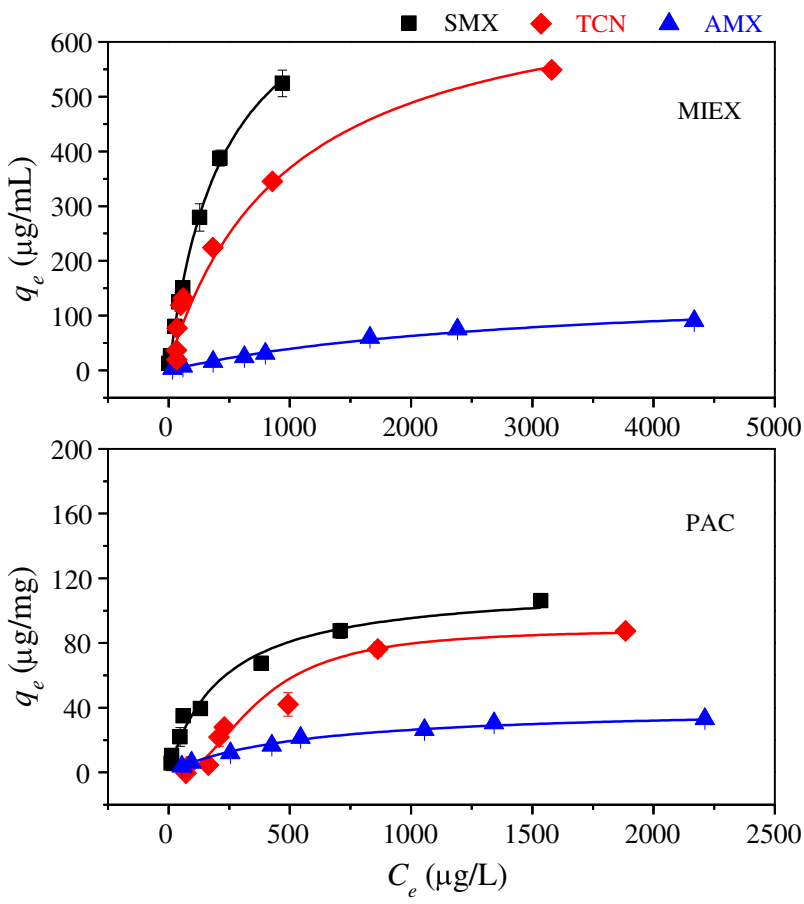

Fig. 2 - Adsorption isotherms of the selected antibiotics on MIEX resin and powdered activated carbon (PAC), respectively. Experimental conditions: temperature $=25 \pm$ $0.5^{\circ} \mathrm{C}$, MIEX resin dosage $=5 \mathrm{~mL} / \mathrm{L}, \mathrm{PAC}$ dosage $=20 \mathrm{mg} / \mathrm{L}$, adsorption time $=30 \mathrm{~min}, C_{o}$, antibiotic $=100,200,500,800$, $1000,2000,3000$, and $5000 \mu \mathrm{g} / \mathrm{L}, \mathrm{pH}$ without any adjustment. Error bars represent the relative percent difference of duplicate experiments.

of three antibiotics on the MIEX resin decreased rapidly when the $\mathrm{pH}$ value decreased from 7 to 3 .

With the $\mathrm{pH}$ value increasing from 7 to 11 , the adsorbed concentrations of the antibiotics on MIEX resin decreased, which could be attributed to the competitive adsorption of hydroxyl ions for the active sites on MIEX resin. Additionally, the excess hydroxyl ions in strong alkaline condition make the surface of MIEX resin negatively charged, which restricts the adsorption of antibiotics onto the surface of MIEX resin due to electrostatic repulsion force (Crini et al., 2007). Other than the small drop (i.e., 16\%) of adsorbed concentration of SMX with $\mathrm{pH}$ increase from 9 to 11, the adsorbed concentrations decreased rapidly by $60 \%$ and $43 \%$ for TCN and AMX, respectively. It is probably attributed to the formation of dianion (at the $\mathrm{pH}$ exceeded the $\mathrm{pK}_{\mathrm{a}, 3}$ ) during the adsorption process, which may occupy more exchange sites on MIEX resin.
The three tested antibiotics contain hydrogen donor and acceptor, such as hydroxyl group, carboxyl group, sulfamide group and amino group, which may form hydrogen bonding with the polar functional groups (e.g., ketone and ammonium moieties) in the polypropylene polymer of the MIEX resin as illustrated in Fig. 4b. More hydroxyl groups gave a stronger hydrogen bonding interaction for the adsorption of TCN on the MIEX resin than AMX, which probably accounted for that the adsorbed concentration of TCN was a little higher than that of AMX under the same condition with MIEX at $\mathrm{pH}=7$.

Therefore, the adsorption capacity on the MIEX resin reflected a comprehensive balance among different influences induced by the physical-chemical mechanism of the target antibiotics (Hubicka and Kolodynska, 2001; Li and SenGupta, 2004).

\subsection{Regeneration of MIEX}

The MIEX resin contains a high proportion of magnetic iron oxide compounds, making fine resin beads agglomerate into larger, fast-settling particles (Humbert et al., 2007). Hence, the used MIEX resin could be easily separated from the treated water by gravity without external magnetic fields. The spent MIEX resins can be regenerated through reverse ion exchange, where contaminants were substituted by chloride ions (Bolto et al., 2004). In this study, the MIEX resin saturated with antibiotics was first regenerated with a $2 \mathrm{~mol} / \mathrm{L} \mathrm{NaCl}$ solution, and then applied to conduct the adsorption experiments. The results indicate that the regenerated MIEX resin showed negligible loss in its adsorption capacity even after seven test cycles (as shown in Appendix A Fig. S4).

\section{Conclusions}

This work investigated the adsorptive removal of three commonly-used antibiotics by MIEX resin. The results indicate that the antibiotic adsorption on MIEX resin was an initially rapid process and reached equilibrium within $30 \mathrm{~min}$. Adsorption kinetics of antibiotics with MIEX resin fitted well with the pseudo-second-order model. The MIEX resin presented adsorption capacities of 789.32, 443.18 and $155.15 \mu \mathrm{g} / \mathrm{mL}$ for SMX, TCN and AMX, respectively. Compared to PAC, the MIEX resin showed higher adsorption capacities and adsorption rates for the tested antibiotics. The solution $\mathrm{pH}$ exerted a strong impact on the adsorption process and the highest adsorption removals of three tested antibiotics were obtained around neutral $\mathrm{pH}$. Anion exchange is the major mechanism involved in the adsorption of antibiotics on the MIEX resin and the formation of hydrogen binding also enhances the adsorption. The MIEX

Table 3 - Parameters for the Langmuir equilibrium adsorption isotherms for antibiotics on MIEX resin and PAC, respectively.

\begin{tabular}{lcccccc} 
Antibiotics & \multicolumn{3}{c}{ MIEX } & & \multicolumn{2}{c}{ PAC } \\
\cline { 2 - 4 } & $q_{\mathrm{m}}(\mu \mathrm{g} / \mathrm{mL})$ & $k_{\mathrm{L}}(\mathrm{L} / \mu \mathrm{g})$ & $R^{2}$ & & $q_{\mathrm{m}}(\mu \mathrm{g} / \mathrm{mg})$ & $k_{\mathrm{L}}(\mathrm{L} / \mu \mathrm{g})$ \\
\hline SMX & 789.32 & $2.16 \times 10^{-3}$ & 0.998 & 104.12 & $7.10 \times 10^{-3}$ & 0.971 \\
TCN & 443.18 & $4.69 \times 10^{-4}$ & 0.993 & 223.97 & $2.61 \times 10^{-3}$ & 0.975 \\
AMX & 155.15 & $3.49 \times 10^{-4}$ & 0.978 & 42.89 & $1.64 \times 10^{-3}$ & 0.993 \\
\hline
\end{tabular}




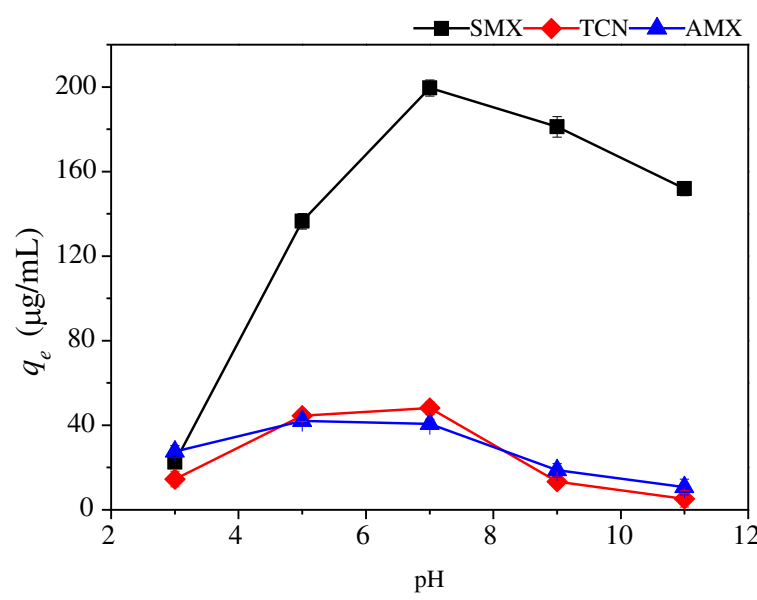

Fig. 3 - Effect of solution pH on the adsorption of selected antibiotics on MIEX resin. Experimental conditions: temperature $=25 \pm 0.5^{\circ} \mathrm{C}$, MIEX resin dosage $=5 \mathrm{~mL} / \mathrm{L}$, adsorption time $=30 \mathrm{~min}, \mathrm{C}_{\mathrm{o} \text {, antibiotic }}=1000 \mu \mathrm{g} / \mathrm{L}$. Error bars represent the relative percent difference of duplicate experiments.

resin can maintain high adsorption efficiencies for antibiotics after regeneration. Therefore, regarding the properties of fast separation, prominent reusability, together with the higher adsorption capacity and adsorption rate, MIEX resin could be a

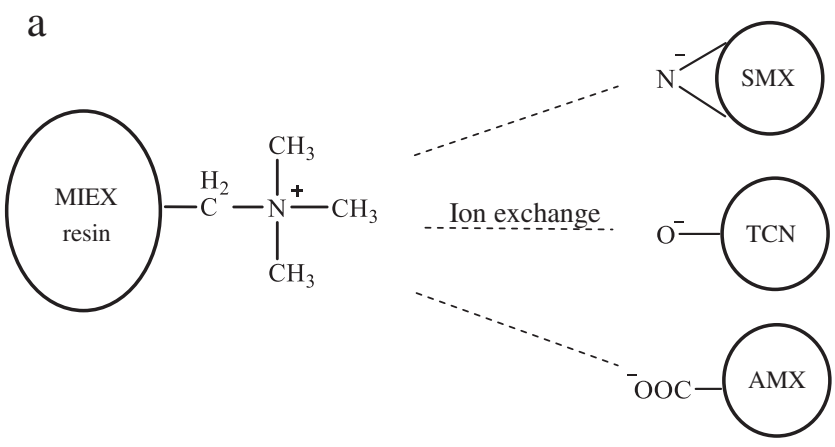

b

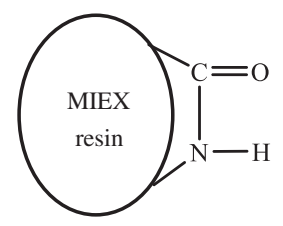

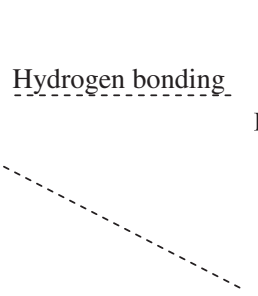

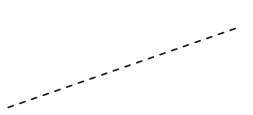

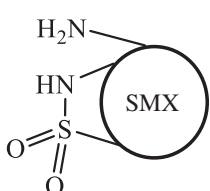<smiles></smiles><smiles>[Y10]C1C(O)C(N)CCCCC2[Z1]N1C2=O</smiles>

Fig. 4 - Proposed mechanisms for antibiotic adsorption on MIEX resin: (a) ion exchange, and (b) hydrogen bonding. promising adsorbent to remove antibiotics in the water treatment process.

\section{Acknowledgments}

This work was supported by the National Natural Science Foundation of China (No. 21107127) and the Ministry of Science and Technology of China (No. 2012AA062606).

\section{Appendix A. Supplementary data}

Supplementary data to this article can be found online at http://dx.doi.org/10.1016/j.jes.2016.03.017.

\section{R E F E R E N C E S}

Abburi, K., 2003. Adsorption of phenol and p-chlorophenol from their single and bisolute aqueous solutions on Amberlite XAD-16 resin. J. Hazard. Mater. 105 (1-3), 143-156.

Adams, C., Wang, Y., Loftin, K., Meyer, M., 2002. Removal of antibiotics from surface and distilled water in conventional water treatment processes. J. Environ. Eng. 128 (3), 253-260.

Baquero, F., Martinez, J.L., Canton, R., 2008. Antibiotics and antibiotic resistance in water environments. Curr. Opin. Biotechnol. 19 (3), 260-265.

Ben, W.W., Qiang, Z.M., Adams, C., Zhang, H.Q., Chen, L.P., 2008. Simultaneous determination of sulfonamides, tetracyclines and tiamulin in swine wastewater by solid-phase extraction and liquid chromatography-mass spectrometry.

J. Chromatogr. A 1202 (2), 173-180.

Bolto, B., Dixon, D., Eldridge, R., 2004. Ion exchange for the removal of natural organic matter. React. Funct. Polym. 60, 171-182.

Boxall, A.B.A., Kolpin, D.W., Halling-Sorensen, B., Tolls, J., 2003. Are veterinary medicines causing environmental risks? Environ. Sci. Technol. 37 (15), 286a-294a.

Boyer, T.H., Singer, P.C., 2005. Bench-scale testing of a magnetic ion exchange resin. For removal of disinfection by-product precursors. Water Res. 39 (7), 1265-1276.

Chen, H., Gao, B., Li, H., 2013. Functionalization, pH, and ionic strength influenced sorption of sulfamethoxazole on graphene. J. Environ. Chem. Eng. 2 (1), 310-315.

Choi, K.J., Kim, S.G., Kim, S.H., 2008. Removal of tetracycline and sulfonamide classes of antibiotic compound by powdered activated carbon. Environ. Technol. 29 (3), 333-342.

Crini, G., Peindy, H.N., Gimbert, F., Robert, C., 2007. Removal of CI basic green 4 (malachite green) from aqueous solutions by adsorption using cyclodextrin-based adsorbent: kinetic and equilibrium studies. Sep. Purif. Technol. 53 (1), 97-110.

Deng, S.B., Ma, R., Yu, Q., Huang, J., Yu, G., 2009. Enhanced removal of pentachlorophenol and 2,4-D from aqueous solution by an aminated biosorbent. J. Hazard. Mater. 165 (1-3), 408-414.

Ding, L., Lu, X., Deng, H.P., Zhang, X.X., 2012. Adsorptive removal of 2,4-dichlorophenoxyacetic acid (2,4-D) from aqueous solutions using MIEX resin. Ind. Eng. Chem. Res. 51 (34), 11226-11235.

Fearing, D.A., Banks, J., Guyetand, S., Eroles, C.M., Jefferson, B., Wilson, D., Hillis, P., Campbell, A.T., Parsons, S.A., 2004. Combination of ferric and MIEX (R) for the treatment of a humic rich water. Water Res. 38 (10), 2551-2558. 
Goddard, A.F., Jessa, M.J., Barrett, D.A., Shaw, P.N., Idstrom, J.P., Cederberg, C., Spiller, R.C., 1996. Effect of omeprazole on the distribution of metronidazole, amoxicillin, and clarithromycin in human gastric juice. Gastroenterology 111 (2), 358-367.

Heberer, T., 2002. Occurrence, fate, and removal of pharmaceutical residues in the aquatic environment: a review of recent research data. Toxicol. Lett. 131 (1-2), 5-17.

Ho, Y.S., McKay, G., 1999. Pseudo-second order model for sorption processes. Process Biochem. 34 (5), 451-465.

Homayoonfal, M., Mehrnia, M.R., 2014. Amoxicillin separation from pharmaceutical solution by $\mathrm{pH}$ sensitive nanofiltration membranes. Sep. Purif. Technol. 130, 74-83.

Hsu, S., Singer, P.C., 2010. Removal of bromide and natural organic matter by anion exchange. Water Res. 44 (7), 2133-2140.

Hubicka, H., Kolodynska, D., 2001. Studies on application of polyacrylate anion-exchangers in sorption and separation of iminodiacetate rare earth element(III) complexes. Hydrometallurgy 62 (2), 107-113.

Huerta-Fontela, M., Galceran, M.T., Ventura, F., 2011. Occurrence and removal of pharmaceuticals and hormones through drinking water treatment. Water Res. 45 (3), 1432-1442.

Humbert, H., Gallard, H., Jacquemet, V., Croué, J., 2007. Combination of coagulation and ion exchange for the reduction of UF fouling properties of a high DOC content surface water. Water Res. 41 (17), 3803-3811.

Humbert, H., Gallard, H., Suty, H., Croue, J.P., 2008. Natural organic matter (NOM) and pesticides removal using a combination of ion exchange resin and powdered activated carbon (PAC). Water Res. 42 (6-7), 1635-1643.

Kim, S.H., Shon, H.K., Ngo, H.H., 2010. Adsorption characteristics of antibiotics trimethoprim on powdered and granular activated carbon. J. Ind. Eng. Chem. 16 (3), 344-349.

Kitis, M., Harman, B.I., Yigit, N.O., Beyhan, M., Nguyen, H., Adams, B., 2007. The removal of natural organic matter from selected Turkish source waters using magnetic ion exchange resin (MIEX (R)). React. Funct. Polym. 67 (12), 1495-1504.

Li, P., Sengupta, A.K., 1998. Genesis of selectivity and reversibility for sorption of synthetic aromatic anions onto polymeric sorbents. Environ. Sci. Technol. 32 (23), 3756-3766.
Li, P., SenGupta, A.K., 2004. Sorption of hydrophobic ionizable organic compounds (HIOCs) onto polymeric ion exchangers. React. Funct. Polym. 60, 27-39.

Machatha, S.G., Yalkowsky, S.H., 2005. Comparison of the octanol/ water partition coefficients calculated by $C \log P((R))$, ACDlogP and KowWin((R)) to experimentally determined values. Int. J. Pharm. 294 (1-2), 185-192.

Neale, P.A., Mastrup, M., Borgmann, T., Schafer, A.I., 2010. Sorption of micropollutant estrone to a water treatment ion exchange resin. J. Environ. Monit. 12 (1), 311-317.

Nikolaou, A., Meric, S., Fatta, D., 2007. Occurrence patterns of pharmaceuticals in water and wastewater environments. Anal. Bioanal. Chem. 387 (4), 1225-1234.

Özacar, M., 2003. Phosphate adsorption characteristics of alunite to be used as a cement additive. Cem. Concr. Res. 33 (10), 1583-1587.

Qiang, Z.M., Adams, C., 2004. Potentiometric determination of acid dissociation constants ( $\mathrm{pK}(\mathrm{a}))$ for human and veterinary antibiotics. Water Res. 38 (12), 2874-2890.

Qiang, Z.M., Bao, X.L., Ben, W.W., 2013. MCM-48 modified magnetic mesoporous nanocomposite as an attractive adsorbent for the removal of sulfamethazine from water. Water Res. 47 (12), 4107-4114.

Sun, G., Xu, X., 1997. Sunflower stalks as adsorbents for color removal from textile wastewater. Ind. Eng. Chem. Res. 36 (3), 808-812.

Watkinson, A.J., Murby, E.J., Kolpin, D.W., Costanzo, S.D., 2009. The occurrence of antibiotics in an urban watershed: from wastewater to drinking water. Sci. Total Environ. 407 (8), 2711-2723.

Weber, W.J., Morris, C.J., 1962. Advances in water pollution research. Proceedings of the First International Conference on Water Pollution Research vol. 2. Pergamon Press, Oxford, p. 231. 